\title{
Chromatic vision in human infants: Conditioned operant fixation to "hues" of varying intensity
}

\author{
M. JOSEPH SCHALLER \\ University of Wisconsin-Madison, Madison, Wisconsin 53706
}

\begin{abstract}
Infants 11-12 weeks old were conditioned using social, visual, and auditory reinforcement to look longer at the "red" (or "green") members of "red-green" pairs. No attempt was made to match intensities, which instead ranged over relative values from 200 to 1 . Thus, wavelength, and not intensity differences, provided the basis for successful discrimination.
\end{abstract}

The suspicion is common that human infants can "see color." Nonetheless, attempts to so demonstrate have failed for over 100 years to yield any positive instance that cannot be explained alternatively on grounds other than discrimination of wavelength (including Fagan, 1974; see Wooten, 1975 and Kessen, Haith, \& Salapatek, 1970 , p. 287). The present study, using a new method, shows that infants 11-12 weeks old indeed possess chromatic vision, and, in addition, that one can control infants' looking behavior by subsequent reinforcement.

All previous attempts to detect chromatic vision in infants have failed to control properly for differences in "brightness" (or perceived luminosity) among different wavelengths of light. The adult human eye (and undoubtedly the infant eye) is differentially sensitive to lights of varying wavelength (Graham, 1965, p. 350), requiring relatively more energy near either end of the visible spectrum than in the middle in order to produce the same apparent luminosity. For research on chromatic vision in infants, the obvious, but flawed, strategy has been to try to match different wavelength stimuli for luminosity so that discrimination merely on the basis of intensity differences presumably would be impossible (cf. previous studies by Chase, 1937; Fagan, 1974; Peiper, 1963; Staples, 1932). This procedure is acceptable (with infants as with adults) only if, for a given subject: (a) there is precise prior knowledge of luminosity as a function of wavelength (b) at the specific intensity levels under test (c) for the specific area of the retina stimulated, and finally (d) one can control the retinal location of such stimulation with accuracy (see Boynton, 1971; Schaller, Note 1).

None of these conditions has been met for infants. Attempts which nonetheless purport to "match" luminosity (usually by substituting the adult sensitivity curve for the unknown infant curve) result in a

Partially supported by a grant from the Wisconsin Alumni Research Foundation and by NICHD Grant HD 00117. This paper is sponsored by David A. Grant, who takes full editorial responsibility for it. Thanks to M. Kuskowski, D. Becker, G. S. Wasserman, R. M. Schaller, L. J. Harris, D. M. Massaro, W. Epstein, F. K. Graham, G. M. Dziadosz, M. Komisar, and the parents who volunteered their infants. tautology: The infant can discriminate the stimuli either on the basis of "hue," if he has chromatic vision, or quite possibly (since he does not necessarily share the adult sensitivity), on the basis of luminosity whether or not he has chromatic vision. [In fact, recent evidence seems to disconfirm the identity of infant and adult luminosity functions (Munsinger \& Banks, 1974; Dobson, Note 2; Teller \& Peeples, Note 3). These studies do not yet provide enough precision for matching, however; and, in addition, both individual and adult/infant discrepancies are greater than detection threshold values, making matching difficult.] Previous reviewers have concluded that studies which "match" perceived intensity on the basis of the adult sensitivity curve could never adequately control the intensity confound (Kessen et al., 1970; Mann, 1964; Pratt, 1954).

To avoid both the necessity of determining the infant luminosity function and the possible consequences of $d$ isparities between infant and adult luminosity functions, the design of the present study did not rely on any prior luminosity equation. Instead, the within-pair relative intensities of "red"-and-"green" pairs of stimuli were systematically varied over a very wide range. Sometimes a "red" stimulus was presumably "brighter" and, at other times, the "green" one was. As a result, the infant could not use luminosity to achieve an apparent wavelength discrimination-he must use "hue" instead.

Even though it is difficult to condition infants, an operant procedure was chosen, because it does not rely on preexisting spontaneous preferences and because a response to either "hue" could be reinforced. Analysis of prior successful infant learning paradigms suggested that eye movements might be a reasonable response to condition (cf. Sameroff, 1971). The advantages of the eye-movement response system are: it can be easily incorporated into operant conditioning paradigms; visual stimuli are not neutral in relation to eye movements; there are preexisting patterns of organized eye-movement behavior; the response appears early, and the system is relatively mature at a gross level even at 


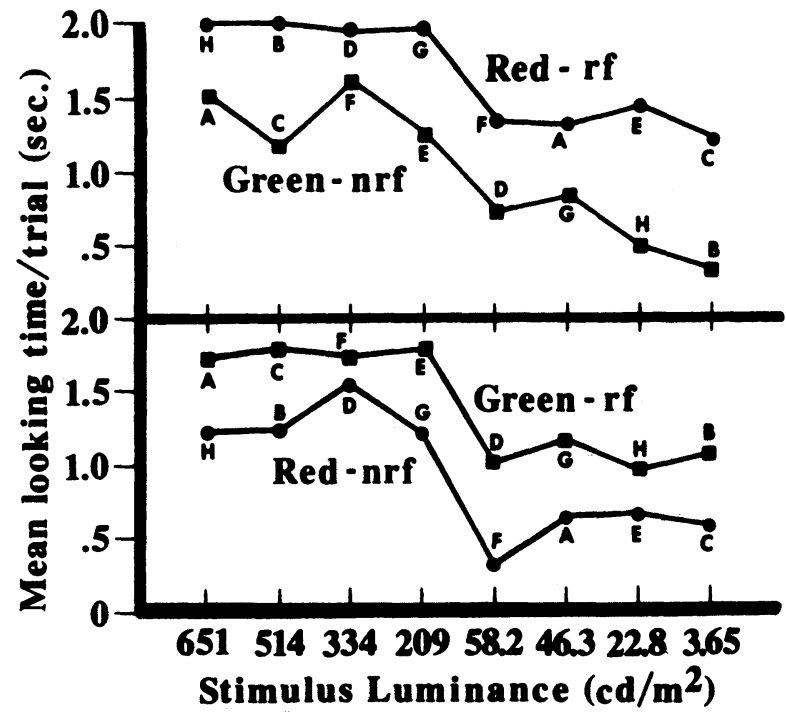

Figure 1. Mean times (seconds) looking per trial to each stimulus. Mean times were taken across all three subjects in each condition on their final testing sessions. Upper graphs are for the "red"-correct infants; lower are for the "green"-correct infants ( $r f=$ reinforced, $n r f=$ nonreinforced $)$. The "red" and "green" stimuli presented together in each pair are indicated by letters A - H. Thus, for example, "red $-46.3 \mathrm{~cd} / \mathrm{m}^{2}$ " appeared with "green-651 cd $/ \mathrm{m}^{2}$ " (Pair A). Stimuli of equal measured luminance were never presented together. Nominal luminances indicated are for the unmasked bright portions of the checkerboard stimuli. Average luminances for the black-and-colored checkerboard were about half these values.

birth; and techniques exist which, for the precision needed here, are easily applicable to its measurement. The present study is the first demonstration of control of fixation in infants by subsequent reinforcement (cf. however, McKenzie \& Day, 1971; Watson, 1969). This technique should be useful for other investigations of infant perception.

\section{METHOD}

\section{Stimuli}

Sixteen "red" and "green" (to adults) chromatic filters were sandwiched with neutral density filters in slide mounts to give luminances that ranged from 3.65 to $651 \mathrm{~cd} / \mathrm{m}^{2}$ in eight steps measured (for reference only) in terms of the adult luminosity function. Edmund Scientific Company chromatic filters No. 823 medium red and No. 871 light green and Kodak neutral density filters were used. Luminances of the unmasked stimuli (measured by a Spectra Pritchard 1960 PR photometer, which has a luminosity function similar to that of the photopically adapted adult fovea) were as indicated on the axis in Figure 1. Equal measured luminance of "red" and "green" stimuli does not imply that the infant necessarily perceives them as equally luminous; however, within each "hue", luminance increases as measured.

Each "red" was paired with a "green" of nominally different luminance (as noted by Letters $\mathrm{A}-\mathrm{H}$ in Figure 1). The series of pairs was counterbalanced for measured luminance (so that for exactly half of the pairs, the "greens" were more intense) and for position as well (across both "hue" and intensity). "Alternation" and "double alternation" responses would result in chance performance for "hue." These slide pairs were then projected onto $12 \times 15-\mathrm{cm}$ rear projection screens $15 \mathrm{~cm}$ to the right and left of center in a black field placed $31 \mathrm{~cm}$ in front of the infant. Checkerboard masks on the back of the rear projection screens resulted in the appearance on the screen either of a black-and-colored $1 / 2$-in.-checkered pattern or of a uniform dark gray (when no stimuli were projected). Average luminances with the checkerboard masks in place were about half the values of the bright portion alone.

The stimuli appeared highly saturated to adult observers; however, note that saturation is not a consideration of importance in the present investigation. Differences in spectral composition would be perceptible as such only to a chromatic observer; for an achromatic observer, they would merely affect luminosity, which varies anyhow, and thus could not provide the basis for a discrimination between "hues."

\section{Subjects}

Four male and four female full-term healthy $2-1 / 2-$ to 2-3/4-month-old infants were tested. Six were white, one was black, and one was Spanish-surnamed. Parents were recruited from the Madison hospital birth registers by letter and follow-up telephone call. Parents were paid parking and transportation expenses. None knew of any chromatic deficiency in their relatives nor had any difficulty pointing to the correct "hue" during training.

\section{Procedure}

Infants were trained to look at only one "hue" in each pair of stimuli, using a variety of individually tailored reinforcers. Sessions lasted from 15 to $60 \mathrm{~min} /$ day (until the infant was judged fussy or sleepy) for 4 to 6 days (until the infant gave significant evidence of a discrimination). Each infant semireclined at about $45 \mathrm{deg}$ in an infant seat with foam supports covering the infant's ears and allowing lateral head rotation up to about $45 \mathrm{deg}$. The supports and sides of the seat prevented the infant's seeing or hearing behind him. A remote observer, who was "blind" as to the correct stimulus, watched the infant's eye movements on a television monitor and recorded them as "left," "right," or "center."

Cumulative correct and incorrect looking times were automatically computed on line. Whenever the cumulative looking time to either stimulus reached a preset criterion of $2.0 \mathrm{sec}$, both stimuli were turned off. Looking time scores automatically were recorded only in the interval before reinforcement when both stimuli were present; data collection was terminated on each trial either when the infant reached criterion on either stimulus or when the maximum trial duration of $6 \mathrm{sec}$ was reached. On trials to be reinforced, the correct stimulus reappeared and flashed, and a "ding-dong"-type doorbell rang, both at a once-per-second rate. The parent or experimenter then moved forward and brought his face down into the infant's visual field, next to the flashing correct stimulus, and smiled, talked, patted, or rubbed the infant and/or presented a pacifier dipped in honey.

During training, the parent or experimenter reached around from behind and out of sight of the infant and prompted him. They pointed to the correct stimulus, snapped their fingers and sometimes called to the infant. As training proceeded, such prompts were given less frequently. They were dropped occasionally on the 3 rd day to see what happened, and usually after the first few trials of the 4th day, but were resumed again if the infant ceased responding. Written records were kept of all prompted trials, as well as those on which (a) the infant cried vocally, (b) the parent inadvertently made any sound, or (c) the infant's position had to be adjusted during the stimulus presentation. All such trials were dropped from the analy sis to avoid bias. In addition, one subject cried so frequently during the first 2 days of training that we could not bring her back for testing. 
Table 1

Total Looking Times (Seconds) for Each Infant

\begin{tabular}{|c|c|c|c|c|c|c|c|c|c|c|}
\hline \multirow[b]{2}{*}{ Subject } & \multirow[b]{2}{*}{$\operatorname{Sex}$} & \multirow[b]{2}{*}{ "Hue" } & \multirow{2}{*}{$\begin{array}{l}\text { Days to } \\
\text { Criterion }\end{array}$} & \multicolumn{3}{|c|}{$\begin{array}{c}\text { (a) } \\
\text { Total Looking Time (Sec) }\end{array}$} & \multicolumn{3}{|c|}{$\begin{array}{c}\text { (b) } \\
\text { Total Looking Time (Sec) }\end{array}$} & \multirow{2}{*}{$\begin{array}{c}\text { Criterion } \\
\text { Session } \\
\text { N Trials }\end{array}$} \\
\hline & & & & Correct & Wrong & $\mathbf{p}$ & Brighter & Dimmer & $\mathbf{p}$ & \\
\hline 1 & $\mathbf{M}$ & $\mathbf{R}$ & 5 & 33.3 & 22.3 & .040 & 35.8 & 19.8 & .004 & 20 \\
\hline 2 & F & $\mathbf{R}$ & 4 & 44.7 & 20.7 & $<.001$ & 44.1 & 21.3 & .002 & 26 \\
\hline 3 & F & $\mathbf{R}$ & 5 & 34.9 & 23.0 & .027 & 34.7 & 23.2 & .038 & 21 \\
\hline 4 & $\mathrm{~F}$ & $\mathrm{G}$ & \multicolumn{4}{|c|}{ Discontinued Day 2, cried continuously } & & & & \\
\hline 5 & M & $\mathrm{G}$ & 3 & 102.6 & 72.6 & .022 & 109.9 & 65.3 & .003 & 70 \\
\hline 6 & M & $\mathrm{G}$ & \multicolumn{7}{|c|}{ Equipment failure, Day 4, no session; Day 5 nonsignificant } & \\
\hline 7 & M & $\mathrm{G}$ & 6 & 31.4 & 15.9 & .0526 & 34.0 & 13.3 & .013 & 21 \\
\hline 8 & $\mathbf{F}$ & G & 5 & 41.8 & 25.7 & .028 & 46.4 & 21.1 & $<.001$ & 28 \\
\hline
\end{tabular}

Note-Rescored times (maximum $2 \mathrm{sec} /$ trial) for each subject on the final day are shown (a) for the reinforced "hue" vs. the nonreinforced "hue" stimuli across all luminances and (b) for the nominally brighter vs. the dimmer stimuli in each pair across both "hues." Significance levels $(p)$ of the Wilcoxon's $T$ for matched pairs are shown for each contrast.

\section{Analysis}

The primary response measure was looking time to the correct "hue" vs. looking time to the incorrect one on each trial. (Per-trial measures of correct and incorrect numbers of looks, mean time per look, and looking time to each stimulus were also recorded and will be presented in a more detailed report elsewhere. These measures corroborated the results from the primary analy sis.)

The Wilcoxon $T$ for matched pairs (Siegel, 1956) was computed for all unprompted trials within each testing session for each infant, rather than for groups, to provide an analysis that would be convincing within individuals, rather than one that relied on a large number of subjects to identify significant effects.

A secondary precaution was taken against any possible bias of the on-line observer: video tapes of all sessions which the primary analysis showed to be successful were reanalyzed. A different observer, who was again "blind" as to which side held the correct stimulus, and in addition, as to when reinforcement was delivered, rescored the sessions while they were played back at one-tenth normal speed.

Although this procedure is very time consuming, it would seem even more advisable than computing interobscrver reliabilities, since it improves the accuracy of scoring by an order of magnitude. In any case, the interobserver correlation coefficient (Spearman $r_{s}$ ) between randomly chosen on-line and rescored sessions was .95 . The rescoring analyses corroborated the original on-line analyses. These more accurate rescored looking times (reported in Table 1) are the basis of all analyses reported here.

\section{RESULTS AND DISCUSSION}

The results indicate chromatic vision: Six of the seven tested infants each showed significantly longer fixation times for the reinforced stimulus set (see Table 1a), thus demonstrating that each had learned the discrimination between the "red" and "green" stimuli. In the case of the seventh infant, an equipment malfunction prevented testing on Day 4; if he had learned anything during the first 3 days of training, he apparently had forgotten it by Day 5.

\section{No Intensity Confound}

Further, the results allow us to dismiss with certainty the possibility of an intensity confound. One might argue that all (or nearly all) members of one set of stimuli could be more luminous to the infant than the other set, so that a discrimination between sets could be based on luminosity. For example, if infants perceive "red" as more luminous, then an apparent "hue" discrimination could be achieved if the "red"-correct infants looked more to the brighter stimuli and if the "green"-correct infants conversely looked more to the dimmer stimuli. However, no such dual pattern of responses occurred (see Table 1 b). Instead, each infant, no matter on which "hue" he had been reinforced, showed significantly longer fixation times overall to both the reinforced "hues" and independently to the nominally brighter members of the pairs. Within the range of intensities used here, this "brightness-preference" might be expected, based on earlier reports (Hershenson, 1964). In the present study, infants looked longer at brighter stimuli, both initially and after training. This is further reason why attempts to equate brightness are suspect. If the matching were not accurate, then infants not only could make a discrimination based on intensity, but would be expected to.

The independence of the "hue" discrimination and the preference for brighter stimuli can be seen more easily by examining responses to individual stimuli (Figure 1). It is clear that if the discrimination were to be based on intensity (say "red" were perceptually brighter), then the greater response to the more intense stimuli within each "hue" should have reversed between the "red"-reinforced and the "green"-reinforced conditions (i.e., the infant must then fixate longer the "dimmer" stimulus within both "hue" groups in the "green"-reinforced condition). Instead, within each "hue" in both conditions, infants showed decreasing looking times as luminance declined, but at every level they continued to fixate the reinforced stimuli longer than the nonreinforced ones. This provides independent verification that the discrimination between "red" and "green" cannot have been based on luminosity 
differences and must have been based on "hue."

This experiment thus provides a positive unequivocal answer to a more-than-100-year-old problem. The human infant can discriminate "red" from "green." It remains to be seen whether this ability extends to other "hues."

\section{REFERENCE NOTES}

1. Schaller, M. J. "Brightness" equation to show infant chromatic vision: Methodological comment. Journal of Experimental Child Psychology. Manuscript submitted for Experimental Child

2. Dobson, M. V. Spectral sensitivity of the 2-month infant as measured by the visually evoked cortical potentional. Dissertation, Brown University, 1975.

3. Teller, D. Y., \& Peeples, D. Grating acuity and color sensitivity in infants. Paper presented to Association for Research in Vision and Ophthalmology Meetings, Sarasota, Florida, April 1974.

\section{REFERENCES}

Boynton, R. M. Color vision. In J. W. Kling and L. A. Riggs (Eds.), Woodworth and Schlosberg's Experimental Psychology (3rd ed.). New York: Holt, Rinehart, and Winston, 1971.

Chase, W. P. Color vision in infants. Journal of Experimental Psy chology, 1937, 20, 203-222.

Fagan, J. F. Infant color perception. Science, 1974, 183, 973-975.

Graham, C. H. Discriminations that depend on wavelength. In C. H. Graham (Ed.), Vision and visual perception. New York: Wiley, 1965.
Hershenson, M. Visual discrimination in the human newborn. Journal of Comparative and Physiological Psychology, 1964, $58,270-276$.

Kessen, W., Haith, M. M., \& Salapatek, P. H. Human infancy: A bibliography and guide. In P. Mussen (Ed.), Carmichael's manual of child psychology. New York: Wiley, 1970.

Mann, I. The development of the human eye. London: British Medical Association, 1964.

McKenzie, B., \& Day, R. H. Operant learning of visual pattern discrimination in young infants. Journal of Experimental Child Psy chology, 1971, 11, 45-53.

Munsinger, H., \& Banks, M. S. Pupillometry as a measure of visual sensitivity among infants, young children, and adults. Developmental Psy chology, 1974, 10, 667-682.

Peiper, A. Cerebral function in infancy and childhood. New York: Consultants Bureau, 1963.

Pratt, K. C. The neonate. In L. Carmichael (Ed.), Manual of child psychology (2nd ed.). New York: Wiley, 1954. Pp. 215-291.

Sameroff, A. J. Can conditioned responses be established in the newborn infant: 1971? Developmental Psychology, 1971, 5, 1-12.

Siegel, S. Non-parametric statistics for the behavioral sciences. New York: McGraw-Hill, 1956.

Staples, R. The responses of infants to color. Journal of Experimental Psy chology, 1932, 15, 119-141.

Watson, J. S. Operant conditioning of visual fixation in infants under visual and auditory reinforcement. Developmental Psy chology, 1969, 1, 508-516.

Wooten, B. R. Infant hue discrimination? Comment on Fagan (1974). Science, 1975, 187, 275-277.

(Received for publication March 29, 1975.) 